\title{
CNR and BER Ranges for the DVB-T2 Reception-Success
}

\author{
Budi Setiyanto $^{1}$, Risanuri Hidayat ${ }^{2}$, I Wayan Mustika ${ }^{3}$, Sunarno $^{4}$ \\ ${ }^{1,2,3}$ Department of Electrical Engineering and Information Technology, Faculty of Engineering, \\ Universitas Gadjah Mada, Yogyakarta, Indonesia \\ ${ }^{4}$ Department of Engineering Physics and Nuclear Engineering, Faculty of Engineering, Universitas Gadjah Mada, \\ Yogyakarta, Indonesia
}

\section{Article Info}

Article history:

Received Nov 7, 2016

Revised Nov 30, 2016

Accepted Jan 8, 2017

\section{Keyword:}

Bit-error-rate

Carrier-to-noise-ratio

DVB-T2

Reception-success

Signal-quality

\begin{abstract}
DVB-T2 (Digital Video Broadcasting Terrestrial Second Generation) reception requires a sufficient quality of the received signal. CNR (carrier-tonoise ratio) and $B E R$ (bit-error-rate) are two of quantities describing the quality. This paper presents the range of each quantity providing a successful reception based on real data obtained by field-measurements. This data was collected from MO (mobile-outdoor) and SI (stationary-indoor) receivingsystems capturing signal sent by some on-air trial transmitters broadcasting services focused on the fixed-receivers. The result indicated that the successful and failed receptions were split into two quite separated (concentrated) ranges of post-decoded $B E R$ and therefore a boundary distinguishing them could be prominently defined. In contrast, they were spread in a wide common range of $C N R$ and pre-decoded $B E R$. Furthermore, the boundary that corresponded to this last quantity was ambiguous. In the case of MO reception as numerical examples, the two split ranges of postdecoded $B E R$ were less than about $10^{-5}$ and more than about $2.7 \times 10^{-4}$ for the successful and failed receptions, respectively, whereas $C N R$ as high as about $14 \mathrm{~dB}$ could be viewed as a soft boundary distinguishing these both reception-success conditions.
\end{abstract}

Copyright (c) 2017 Institute of Advanced Engineering and Science. All rights reserved.

Corresponding Author:

Budi Setiyanto,

Department of Electrical Engineering and Information Technology,

Faculty of Engineering, Universitas Gadjah Mada,

Jln. Grafika 2 Kampus UGM, Sleman, Yogyakarta, 55281, Indonesia.

Email: budi_setiyanto@ugm.ac.id

\section{INTRODUCTION}

The performance of a communication system can be evaluated from the quality of the received signal. Two quantities commonly used to describe the quality are $C N R$ and $S N R$ (signal-to-noise ratio). In digital communication systems, some of other describing quantities are BER [1],[2], SER (symbol-error rate) [2], and MER (modulation-error-ratio). Therefore, these quantities are also used to describe the digital television (DTV) received signal quality [3]-[5]. As one of DTV standards [6], DVB-T2 [7],[8] has adopted in many countries. Improving the reception-quality can be carried-out by several schemes, such as by implementing a MISO (multiple-input single-output) technique [9] at the transmitting-side, deploying a SFN (single-frequency-network) [10],[11] or OCR (on-channel repeater) [12],[13] in the network segment, or employing a multiple-antenna (MA) method [14],[15] at the receiving-end. Several field-measurements and field-trials of DVB-T2 have also been carried-out [16]-[21]. Based on the obtained data, the required $S N R$ threshold [19] and minimum $C N R$ [16] are estimated, by referring to the FBER (frame block error rate) and QEF (quasi error-free) criteria, respectively. By defining the successful reception as a condition when the receiver produces a moving picture, then the relationship of either $C N R$ or $B E R$ and reception-success is probabilistic, not deterministic [20],[21]. However, the range of either $C N R$ or BER providing a successful 
reception has not been further explored. Therefore, this paper presents an investigation on those ranges, based on field-measurement results using a commercial consumer receiver. Such investigation is useful to, for example, implementing the MA technique at the receiving-end. The remainder of this paper is organized as follows. After review of DVB-T2 in Section 2, Section 3 and 4 explain the experiment method and result, respectively. Finally, Section 5 presents the conclusion.

\section{DVB-T2}

\subsection{System Overview}

In contrast to analog broadcasting technology where one frequency channel, as wide as $8 \mathrm{MHz}$ for example, conveys only one TV program, DVB-T2 is capable of carrying several programs in an equal bandwidth. At the DVB-T2 transmitter-side, several programs can be packaged into a physical-layer-pipe (PLP). Even, in a multi-PLP system, several PLPs are packaged further into a baseband (BB)-frame format. Finally, this format is transmitted using OFDM modulation, where a stream (sequence) of bits or symbols to be sent is split into several sub-streams, each of which modulates a dedicated sub-carrier frequency, different from the frequency of other sub-carriers. At every symbol duration, all sub-carriers are orthogonal to each other [26].

Bit processing in each PLP consists of FEC (forward error control) encoding, interleaving, and QAM (quadrature amplitude modulation) constellation-mapping. Several options provided in this stage are the QAM order, interleaving depth, and FEC coding rate. Several options are also avaiable in the OFDM stage, involving fast Fourier transform (FFT) size (mode), guard interval (GI) ratio, and pilot pattern. FECs used are $\mathrm{BCH}$ (Bose-Chaudhuri-Hocquenghem) and LDPC. Front stage in the receiving-end is a tuner (RFunit) converting the incoming signal to BB-OFDM. A FFT processor at the next stage demodulates this signal. Symbol processing including QAM-decoding, de-interleaving, and FEC decoding carrying-out after the desired PLP is extracted produces the original bit-stream. This bit-stream is decoded to recover the video and audio signals. These signals are finally manifested to the corresponding picture and sound outputs, respectively.

\subsection{Signal Quality}

Ordered from the earliest stage to the latest one at the receiver, $C N R, M E R$, and $B E R$ are three of quantities describing the signal quality, respectively. When AWGN (additive white Gaussian noise) is the only impairment presents, then relationships among these three quantities are consistent, where the higher the first two or the lower the last one, the better the signal. On the other hand, when a multipath fading exists, such consistence is probably violated, as informed by a previous work result [18]. A receiver is capable of estimating (computing) those quantities, by which the method of estimation applied affects its accuracy. As an illustration, re-encoding the decoder output gives an estimated delayed version of its pre-decoded bitstream, and comparing these both streams gives the estimated pre-decoded BER. CNR, which originally should be measured at the RF (radio frequency) or modulated stage, can be estimated from the $S N R$ at the BB stage, based on the scattering constellation diagram [27].

\section{RESEARCH METHOD}

\subsection{Equipment}

Equipment involed in this research is illustrated in Figure 1 (a). It mainly consisted of an antenna and a consumer-type digital television (DTV) receiver (Rx). In addition, MO reception required an antenna booster and a video camera. This DTV produces moving picture only when its reception is successful. It also provides an additional option of displaying several system information items at the foreground, where the background is the picture itself. Some of these items are $C N R$ and $B E R$, by which $C N R=0$ or $B E R=1$ indicated an occurrence of no signal detected or erroneous measurement. $C N R$, pre-LDPC-decoding $B E R$ (further notated as $B E R_{\mathrm{A}}$ ), post-LDPC-decoding $B E R$ (further notated as $B E R_{\mathrm{B}}$ ) were three quantities, as well as the reception-success, investigated in this research.

\subsection{SI Reception}

Figure 1(b) illustrates the SI reception experiment including the field-measurement and visualobservation works. Antenna was placed quite close to the receiver. In a receiver location, antenna position could be systematically shifted into $x, y$, and $z$ direction-components with their corresponding shifting-steps at $20 \mathrm{~cm}, 20 \mathrm{~cm}$, and $10 \mathrm{~cm}$, respectively. The number of steps including an initial position (as reference) in these direction-components included three, three, and five, respectively. Therefore, there were as many as $3 \times$ $3 \times 5=45$ possible antenna positions in a location receiver. At each position, antenna could also be 
horizontally rotated for pointing it to any azimuth (orientation) angle $(\phi)$, where it was set to ten degrees per rotation step to give as many as $360 / 10=36$ orientation-angles. By defining every position-orientation as a spatial-sample, $45 \times 36=1620$ samples were available. At each sample, the DTV display was quite stationary, and therefore the data could be directly extracted and tabulated from the display. The TV channel observed was number 27 (518 - 526 MHz, 8K-mode FFT, 1/32 GI ratio, 16-QAM).

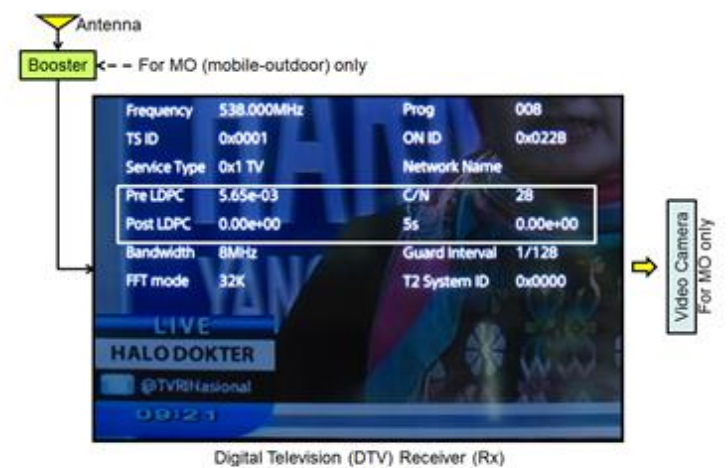

(a)

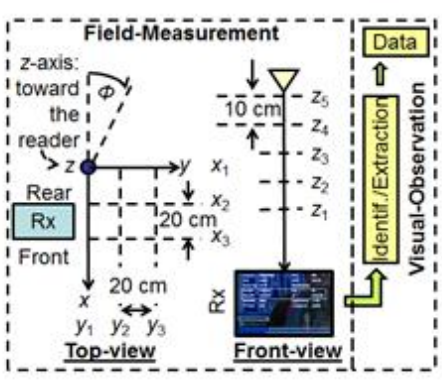

(b)

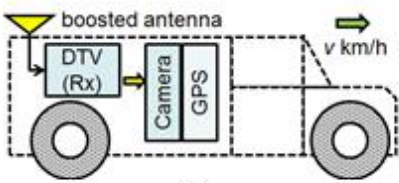

(c)

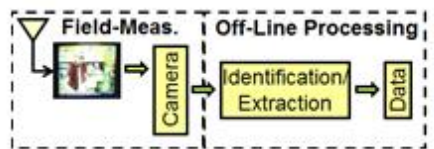

(d)

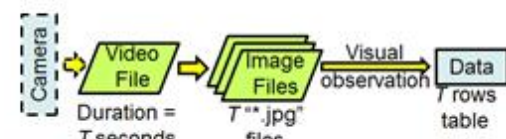

(e)

Figure 1. The illustration of the research method: (a) equipment, (b) SI procedure, (c) MO fieldmeasurement, (d) MO procedure, and (e) MO off-line processing of each video file

\subsection{MO Reception}

The MO reception experiment is illustrated in Figure 1 (c), (d), and (e). Figure 1 (c) describes the field-measurement work. In this work, the equipment was installed on a car (automobile). The boosted antenna was mounted at the outside top-roof, whereas the receiver was the in-cabin unit. Notation " $v(\mathrm{~km} / \mathrm{h})$ " informs that the car travelled several route-segments while the receiving-system was tuned to receive a TV channel. The DTV display varied during the measurement, and therefore a video camera was required to record it. Number 47 (678 - $686 \mathrm{MHz}, 8 \mathrm{~K}$-mode FFT, 1/32 GI ratio, 64-QAM) was the observed TV channel.

Off-line processing shown in Figure 1 (d) intended to identify the reception-success and extract the required quantities $(C N R$ and $B E R$ ) from each video-file. Figure 1 (e) shows the detail of this process. Firstly, a $T$-second duration video-file was converted into a series of $T$ image-files. Such conversion is equivalent to sampling the video-file with $1 \mathrm{~Hz}$ sampling-rate or one frame per second. Secondly, visual-observation work on each image-file extracted those three items and decided whether the reception was successful or failed. Finally, the data was tabulated.

\subsection{Statistical Analysis}

Diagram in Figure 2 illustrates the flow of the statistical analysis. All samples were organized into two groups: one containing all of the successful-reception samples, and another one containing all failedreception ones. In each group, they were sorted by referring to the $C N R$ and $B E R$, respectively, where 
samples that had $C N R=0$ or $B E R=1$ were unusable and therefore eliminated. Having been sorted, they were arranged in an ascending order from $k=1$ for the lowest $C N R(B E R)$ to $k=K$ for the highest one, where $K_{1}$, $K_{2}$, and $K_{3}$ were the values of $K$ that corresponded to the $C N R, B E R_{\mathrm{A}}$, and $B E R_{\mathrm{B}}$, respectively. The number of the usable samples after the sorting process was notated as $U(i, j), i=0,1, j=1,2,3$. For each $k$, the number of the successful and failed receptions samples were $s(1, j, k)$ and $s(0, j, k)$, respectively, and the sum was $V(j$, $k$ ). The aggregate number of the usable samples according to its sorting-quantity was $S(j)$. Therefore,

$$
\begin{aligned}
& U(i, j)=\sum_{k=1}^{K_{j}} s(i, j, k) ; \quad i=0,1 ; \quad j=1,2,3 \\
& V(j, k)=s(1, j, k)+s(0, j, k) ; \quad j=1,2,3 ; \quad k=1,2,3, \ldots, K_{j} \\
& S(j)=U(1, j)+U(0, j)=\sum_{k=1}^{K_{j}} V(j, k) ; \quad j=1,2,3
\end{aligned}
$$

The signed probability density function $(p d f)$ was estimated by using

$$
f(i, j, k)=(-1)^{(i+1)} \frac{s(i, j, k)}{U(i, j)} ; \quad i=0,1 ; \quad j=1,2,3 ; \quad k=1,2,3, \ldots, K_{j}
$$

In equation (4), the result that belonged to the failed-reception was signed by -1 (multiplied by $(-1)^{(i+1)}$ ) to inform that such reception was a condition opposite to that of the successful one.

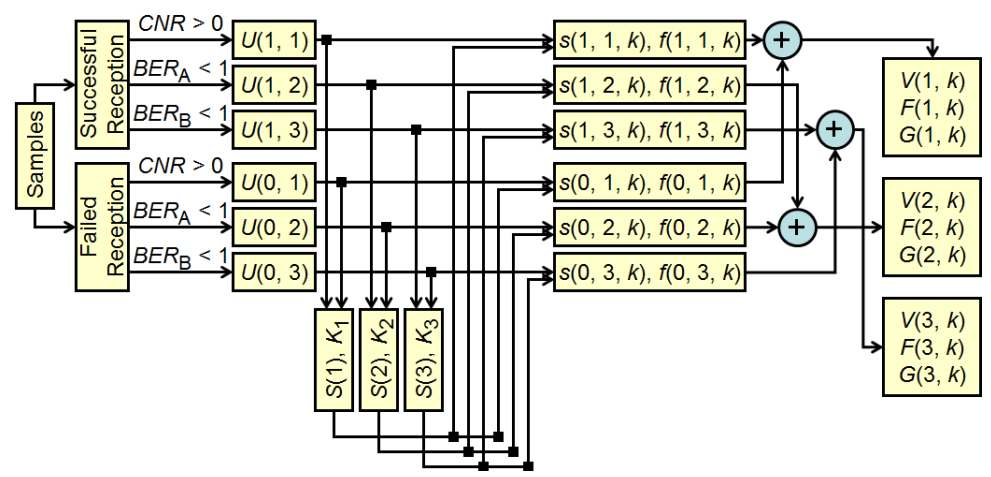

Figure 2. The diagram of the statistical analysis

The successful-group stated that the portion (probability) of successful-reception for each $k$ was as high as $f(1, j, k)$, whereas the failed-group stated that the portion of failed-reception was as high as $f(0, j, k)$. Factually, there was no successful-sample in the failed-group, and vice versa, and therefore it could not be concluded whether the reception given by this $k$ was either successful or failed. On the other hand, the investigation conducted in this experiment examined every value of $k$ and decided whether it was potentially successful or failed. Therefore, an alternative way-out was formulated as follows.

Adding $f(0, j, k)$ to its $f(1, j, k)$ counterpart gave the net signed $p d f$, which could be viewed as a statistical estimation of the portion of the successful-reception for a $k$. A negative result indicated that the reception was expectably failed with the portion as high as the magnitude of this result. Therefore, the net signed $p d f$ was

$$
F(j, k)=f(1, j, k)+f(0, j, k) ; \quad j=1,2,3 ; \quad k=1,2,3, \ldots, K_{j}
$$


An additional function computing the cumulative of the net signed $p d f$ was defined as

$$
G(j, l)=\sum_{k=1}^{l \leq K_{j}} F(j, k) ; \quad j=1,2,3
$$

\section{RESULT}

\subsection{Description}

As an illustration, Table 1 lists ten samples data showing that a failed reception could occur even at a higher $C N R$ or a lower $B E R$ rather than the successful one. For example, samples number 1 and $2(n=1,2$; $C N R=12 \mathrm{~dB}$ and $B E R_{\mathrm{A}}=2.72 \times 10^{-2}$ ) were failed although their $C N R$ were higher or their $B E R_{\mathrm{A}}$ were lower rather than samples number 5, 6, and $7\left(n=5,6,7 ; C N R=11 \mathrm{~dB}<12 \mathrm{~dB}\right.$ and $\left.B E R_{\mathrm{A}}>2.72 \times 10^{-2}\right)$. Similar facts were also indicated by the $B E R_{\mathrm{B}}$ between $n=1,2\left(B E R_{\mathrm{B}}=2.70 \times 10^{-4}\right)$ versus $n=5\left(B E R_{\mathrm{B}}=9 \times 10^{-4}>\right.$ $\left.2.70 \times 10^{-4}\right)$ or between $n=9\left(B E R_{\mathrm{B}}=1.20 \times 10^{-4}\right)$ versus $n=6,7\left(B E R_{\mathrm{B}}=1.60 \times 10^{-4}>1.20 \times 10^{-4}\right)$.

Table 1. An example of ten samples data

\begin{tabular}{ccccc}
\hline $\begin{array}{c}\text { Smpl } \\
(n)\end{array}$ & $\begin{array}{c}\text { Reception } \\
\text { 1: successful } \\
\text { 0: failed }\end{array}$ & $\begin{array}{c}C N R \\
(\mathrm{~dB})\end{array}$ & $\begin{array}{c}B E R_{\mathrm{A}} \\
\left(\times 10^{-2}\right)\end{array}$ & $\begin{array}{c}B E R_{\mathrm{B}} \\
\left(\times 10^{-4}\right)\end{array}$ \\
\hline 1 & 0 & 12 & 2.72 & 2.70 \\
2 & 0 & 12 & 2.72 & 2.70 \\
3 & 1 & 16 & 3.21 & 2.50 \\
4 & 1 & 16 & 3.21 & 2.50 \\
5 & 1 & 11 & 3.46 & 9.00 \\
\hline
\end{tabular}

\begin{tabular}{ccccc}
\hline $\begin{array}{c}\text { Smpl } \\
(n)\end{array}$ & $\begin{array}{c}\text { Reception } \\
\text { 1: successful } \\
\text { 0: failed }\end{array}$ & $\begin{array}{c}C N R \\
(\mathrm{~dB})\end{array}$ & $\begin{array}{c}B E R_{\mathrm{A}} \\
\left(\times 10^{-2}\right)\end{array}$ & $\begin{array}{c}B E R_{\mathrm{B}} \\
\left(\times 10^{-4}\right)\end{array}$ \\
\hline 6 & 1 & 11 & 2.91 & 1.60 \\
7 & 1 & 11 & 2.91 & 1.60 \\
8 & 1 & 7 & 2.83 & 1.20 \\
9 & 0 & 7 & 2.83 & 1.20 \\
10 & 0 & 10 & 3.23 & 2.20 \\
\hline
\end{tabular}

\subsection{Estimation of Ranges}

The complete field-observation obtained 540 samples at a receiver location and 2810 samples from two travelling route-segments in the SI and MO receptions, respectively. Table 2 lists a part of the MO reception data, sorted based upon the $C N R$. Table 3 shows the summary of the statistics of the complete result and Table 4 lists several graphs for the MO result where the range of $B E R_{\mathrm{B}}>3.2 \times 10^{-4}$ was punctured from the graphs. Furthermore, in the graphs that corresponded to the signed $p d f$ and cumulative of the signed $p d f$, all of the highest magnitudes were scaled (normalized) to 1.

Table 2. A part of the MO reception data, sorted based upon the $C N R(j=1)$

\begin{tabular}{|c|c|c|c|c|c|c|c|}
\hline \multirow{3}{*}{$k=C N R(\mathrm{~dB})$} & \multicolumn{3}{|c|}{ Number of Usable Samples $(S(j))$} & \multicolumn{4}{|c|}{ Signed $p d f$} \\
\hline & \multicolumn{2}{|c|}{$s(i, j, k)$} & \multirow[b]{2}{*}{$\underset{(V(j, k))}{\operatorname{Sum}}$} & \multicolumn{2}{|c|}{$f(i, j, k)$} & \multirow{2}{*}{$\begin{array}{c}\text { Net } \\
(F(j, k))\end{array}$} & \multirow{2}{*}{$\begin{array}{l}\text { Cumulative } \\
\qquad(G(j, k))\end{array}$} \\
\hline & $\begin{array}{l}\text { Successful } \\
\quad(i=1)\end{array}$ & $\begin{array}{l}\text { Failed } \\
(i=0)\end{array}$ & & $\begin{array}{l}\text { Successful } \\
\quad(i=1)\end{array}$ & $\begin{array}{l}\text { Failed } \\
(i=0)\end{array}$ & & \\
\hline$\ldots$ & $\ldots$ & $\ldots$ & $\ldots$ & $\ldots$ & $\ldots$ & $\ldots$ & $\ldots$ \\
\hline 13 & 7 & 110 & 117 & 0.0158 & -0.0649 & -0.0491 & -0.8018 \\
\hline 14 & 48 & 150 & 198 & 0.1081 & -0.0884 & 0.0197 & -0.7822 \\
\hline$\ldots$ & $\ldots$ & $\ldots$ & $\ldots$ & $\ldots$ & $\ldots$ & $\ldots$ & $\ldots$ \\
\hline \multirow{2}{*}{$22 \stackrel{\cdots}{\left(=K_{1}\right)}$} & 2 & 0 & 2 & 0.0045 & 0 & 0.0045 & $8 \mathrm{E}-17$ \\
\hline & $444(=U(1,1))$ & $1696(=U(0,1))$ & $2140(=S(1))$ & & & & \\
\hline
\end{tabular}

Table 3. The complete result statistics summary

\begin{tabular}{|c|c|c|c|c|c|c|c|c|c|}
\hline \multirow[b]{2}{*}{$j$} & \multirow[b]{2}{*}{$k=1,2,3, \ldots, k_{\max }$} & \multicolumn{4}{|c|}{$\begin{array}{l}\text { MO, } 2810 \text { samples } \\
\text { Number of Usable Samples }\end{array}$} & \multicolumn{4}{|c|}{$\begin{array}{l}\text { SI, } 540 \text { samples } \\
\text { Number of Usable Samples }\end{array}$} \\
\hline & & $k_{\max }$ & $\begin{array}{l}U(i, \\
\text { Successful } \\
(i=1)\end{array}$ & $\begin{array}{l}\text { Failed } \\
(i=0)\end{array}$ & $\begin{array}{c}\text { Sum } \\
S(j)\end{array}$ & $k_{\max }$ & $\begin{array}{l}U(i, \\
\text { Successful } \\
(i=1)\end{array}$ & $\begin{array}{c}\text { Failed } \\
(i=0)\end{array}$ & $\begin{array}{l}\text { Sum } \\
S(j)\end{array}$ \\
\hline 1 & $k=C N R(\mathrm{~dB})$ & $K_{1}=22$ & 444 & 1696 & 2140 & $K_{1}=16$ & 342 & 174 & 516 \\
\hline 2 & $k=1+10^{3} B E R_{\mathrm{A}}$ & $K_{2}=93$ & 440 & 1051 & 1491 & $K_{2}=171$ & 342 & 37 & 379 \\
\hline 3 & $k=1+10^{5} B E R_{\mathrm{B}}$ & $K_{3}=4201$ & 442 & 1055 & 1497 & $K_{3}=41$ & 342 & 27 & 369 \\
\hline
\end{tabular}


In the MO reception, as an illustration, a sorting process based on the $C N R$ produced 444 usable successful samples. This number was reduced to 442 and 440 when the sorting processes were referred to the $B E R_{\mathrm{A}}$ and $B E R_{\mathrm{B}}$ due to the elimination of two and four samples that had $B E R=1$ in those corresponding quantities, respectively. Such reductions also occurred for the failed samples from 1696 to 1051 and 1055 , respectively. As shown in these tables, the ranges of usable samples were $1 \leq C N R \leq 22,0 \leq B E R_{\mathrm{A}} \leq 9.2 \times$ $10^{-2}$, and $0 \leq B E R_{\mathrm{B}} \leq 4.201 \times 10^{-2}$. Figure 3 presents several graphs that corresponded to the SI reception. The graphs of the number of the usable samples in Table 4 and Figure 3.

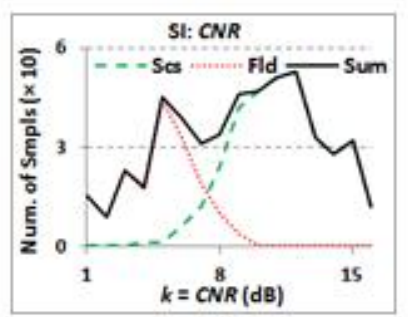

(a)

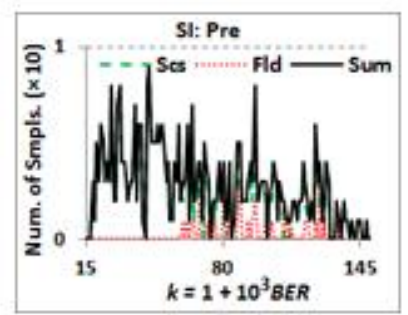

(b)

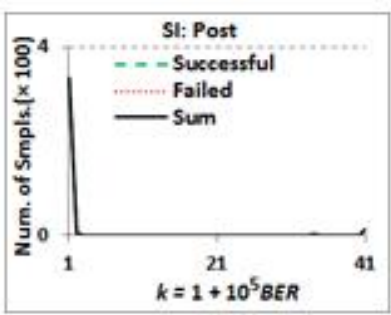

(c)

Figure 3. The number of usable samples $(s(i, j, k), V(j, k))$ obtained in the SI experiment, sorted by: (a) $C N R$, (b) $B E R_{\mathrm{A}}$, and (c) $B E R_{\mathrm{B}}$

Figure 3 shows that the number of the usable samples was not uniformly distributed, but most of the them were spread at the middle-ranges of the $C N R$ and $B E R_{\mathrm{A}}$ - approximating the bell-shaped normal probability-distribution - and were concentrated only at the edge-ranges of the $B E R_{\mathrm{B}}$. Therefore, the LDPCdecoding could simply be viewed as a process of splitting the widely spread $B E R_{\mathrm{A}}$ samples into two concentrated groups, where the successful and failed samples were concentrated around a very low and very high $B E R_{\mathrm{B}}$ values, respectively. As a result, the boundary $(B)$ of $B E R_{\mathrm{B}}$ distinguishing the successful receptions from the failed ones could be prominently determined. Graph \#13 shows that it could be flexibly shifted from $10^{-5}$ to $2.7 \times 10^{-4}$, approximately.

Table 4. Several graphs describing the statistical characteristics of the MO usable samples

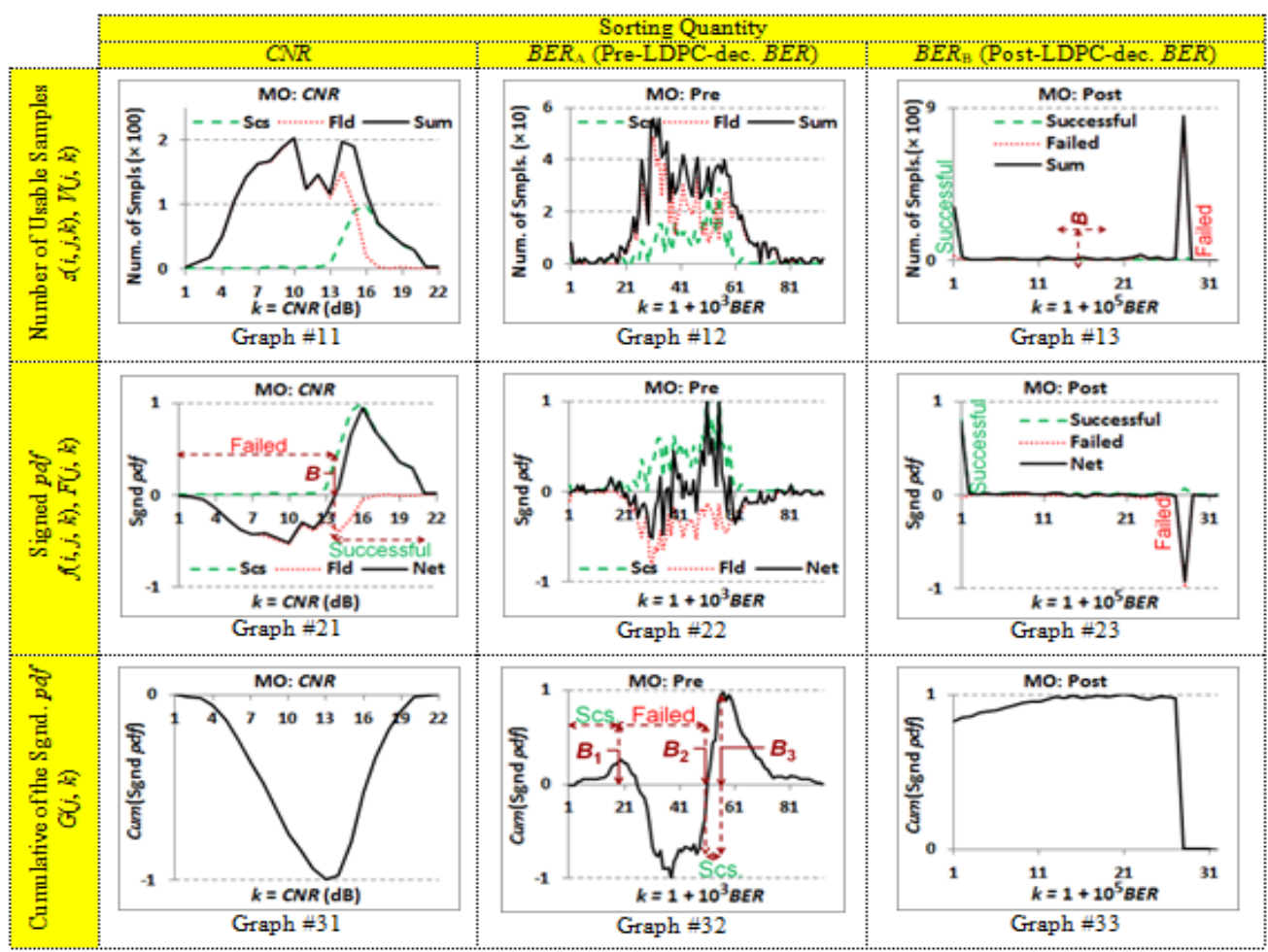


Graph \#21 shows that the boundary that corresponded to the $C N R$ approximated $14 \mathrm{~dB}$. However, a gradual (not an abrupt) change of the curve around this boundary indicates that it was not as prominent as the one estimated from the $B E R_{\mathrm{B}}$. The boundary estimated based on the $B E R_{\mathrm{A}}$ was ambiguous or confusing due to the alternating ranges giving the successful and failed receptions, as shown in Graph \#32. Deciding $B_{1} \approx$ $1.8 \times 10^{-2}$ as the upper bound of successful reception was not supported by enough number of samples, and therefore $B_{3} \approx 5.5 \times 10^{-2}$ might be more appropriate rather than it.

Figure 4 represents several graphs comparing the SI and MO reception results, where $B_{\mathrm{SI}}$ and $B_{\mathrm{MO}}$ were the boundaries that corresponded to the SI and MO, respectively. Figure 4(b) shows that the $B E R_{\mathrm{A}^{-}}$ based $B_{\mathrm{SI}}$ could be uniquely estimated, indeed, and its prominence was comparable to that of the $C N R$. Alternating curve that corresponded to the MO $B E R_{\mathrm{A}}(\mathrm{Graph} \# 32)$ may also indicate the severity of the burst error due to the deep fading in mobile environment. $B_{\mathrm{MO}}>B_{\mathrm{SI}}$ and $B_{\mathrm{MO}}<B_{\mathrm{SI}}$ respectively determined based on the $C N R$ and $B E R\left(B E R_{\mathrm{A}}\right.$ and $\left.B E R_{\mathrm{B}}\right)$ indicated that the quality of the received signal required by the $\mathrm{MO}$ reception was higher than that of by the SI one. It was reasonable by considering the consequence of not only the receiver mobility, but also the QAM-order. As explained before, the order of QAM used by the TV channels observed in the MO reception experiment (64-QAM) was higher than that of in the SI one (16QAM).

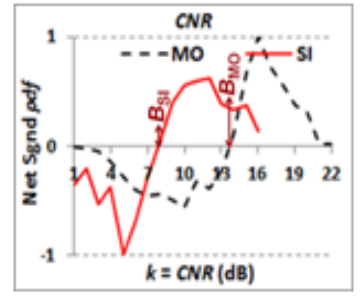

(a)

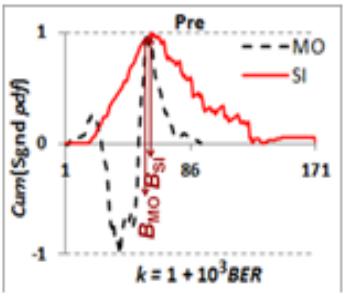

(b)

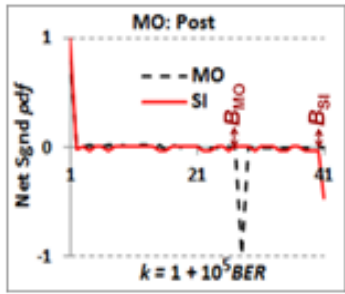

(c)

Figure 4. The comparison of several statistics between the SI and MO experiment results: (a) $C N R$-sorted

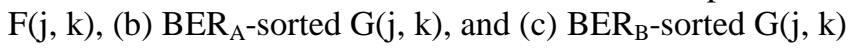

\section{CONCLUSION}

The reception-success of a DVB-T2 receiver is dependent upon the quality of the received signal. $C N R$ and $B E R$ are two of quantities representing the quality. In a multipath-faded radio channel, the relationships of reception-success to $C N R$ and $B E R$ are probabilistic.The result indicated that the successful and failed receptions were split into two quite separated (concentrated) ranges of the post-decoded BER; therefore, a boundary distinguishing them could be prominently defined. In contrast, they were spread in a wide common range of the $C N R$ and pre-decoded BER. Furthermore, the boundary that corresponded to this last quantity was ambiguous. In the case of MO reception, as the numerical examples, those two split ranges of the post-decoded $B E R$ were less than about $10^{-5}$ and more than about $2.7 \times 10^{-4}$ for the successful and failed receptions, respectively, whereas $C N R$ as high as about $14 \mathrm{~dB}$ could be viewed as a soft boundary distinguishing these both reception-success conditions.

\section{ACKNOWLEDGMENT}

The authors would like to thank the Ministry of Research, Technology, and Higher Education, Republic of Indonesia, for providing part of the financial support for the research, which leads to this publication. In addition, the authors would like to acknowledge the supports from the staffs and laboratory assistants of High Frequency System Laboratory, Department of Electrical Engineering and Information Technology, Universitas Gadjah Mada, during the laboratory experiments.

\section{REFERENCES}

[1] H. Zhang, et al., "Performance Analysis of Different Modulation Techniques for Free-Space Optical Communication System," TELKOMNIKA, vol/issue: 13(3), pp. 880-888, 2015.

[2] F. Khair, et al., "Performance Analysis of Digital Modulation for Coherent Detection of OFDM Scheme on Radio over Fiber System," Int. J. Electr. Comput. Eng., vol/issue: 6(3), pp. 1086-1095, 2016.

[3] R. Instrument, "Understanding Digital TV," 2015.

[4] "Georgia Set Top Box Specification," 2014. 
[5] E. Haryatmi, et al., "The Design and Performance Analysis of DTMB System," TELKOMNIKA, vol/issue: 14(3), pp. 873, 2016.

[6] M. El-Hajjar and L. Hanzo, "A Survey of Digital Television Broadcast Transmission Techniques," IEEE Commun. Surv. Tutorials, vol/issue: 15(4), pp. 1924-1949, 2013.

[7] I. Eizmendi, et al., "DVB-T2: The Second Generation of Terrestrial Digital Video Broadcasting System," IEEE Trans. Broadcast., vol/issue: 60(2), pp. 258-271, 2014.

[8] Y. J. Woo, et al., "Design and Realization of Multiplexing System for Fixed/Mobile Next-Generation Broadcasting Service in Network Free Environment," Int. J. Electr. Comput. Eng., vol/issue: 5(3), pp. 531-538, 2015.

[9] M. J., et al., "DVB-T2 MISO/SISO Receiver Performance Limits in Single Frequency Networks: Practical Results," in IEEE International Symposium on Broadband Multimedia Systems and Broadcasting (BMSB), 2013.

[10] C. Li, et al., "Planning Large Single Frequency Networks for DVB-T2," IEEE Trans. Broadcast., 2015.

[11] M. M. Anis, et al., "Analyzing the Coverage of the Single Frequency Broadcast Network for Handheld Receivers," in The 10th Annual IEEE CCNC- Work-in-Progress, pp. 689-692, 2013.

[12] K. Salehian, et al., "On-Channel Repeater for Digital Television Broadcasting Service," IEEE Trans. Broadcast., vol/issue: 48(2), pp. 97-102, 2002.

[13] A. S. Engineering, "The feasibility of DVB-T on-channel repeaters for coverage repair on Channel 60," 2009.

[14] C. Akamine, et al., "Field Trial for Brazilian DTV Using Space Diversity," in IEEE International Symposium on Broadband Multimedia Systems and Broadcasting (BMSB), pp. 1-11, 2010.

[15] J. L. Sánchez, et al., "On the Provisioning of Mobile Digital Terrestrial TV Services to Vehicles with DVB-T," IEEE Trans. Broadcast., vol/issue: 58(4), pp. 642-647, 2012.

[16] M. Slimani, et al., "Results of the DVB-T2 Field Trial in Germany," IEEE Trans. Broadcast., vol. 61, pp. 177-194, 2015.

[17] F. A. Contreras, et al., "DVB-T2 Field Trials Results for Portable Indoor Reception in Colombia," in IEEE Latin America Conference on Communications (LATINCOM), pp. 1-5, 2014.

[18] B. Setiyanto, et al., "Identifikasi Pengaruh Lintasan-Jamak pada DVB-T2 Berdasar Uji Penerimaan Siaran," JNTETI, vol/issue: 5(2), pp. 83-92, 2016

[19] C. Regueiro, et al., "Field Trials-Based Planning Parameters for DVB-T2 Indoor Reception," IEEE Trans. Broadcast., vol. 61, pp. 251-262, 2015.

[20] B. Setiyanto, et al., "Spatial-Variation of DVB-T2 Signal at the Receiver- Location," in The 6th International Annual Engineering Seminar (InAES2016), pp. 221-226, 2016.

[21] B. Setiyanto, et al., "Probabilistic-Relationships in the DVB-T2 Mobile- Reception Signal Received from a FixReception Mode Broadcasting Service," in The 6th International Annual Engineering Seminar (InAES2016), pp. 177-182, 2016.

[22] T. S. Rappaport, "Wireless Communications: Principles and Practices," New Jersey, Prentice-Hall, Inc., 1993.

[23] S. Haykin and M. Moher, "Modern Wireless Communication," New Jersey, Pearson Education Inc., 2005.

[24] N. Madhu, "Note on Measures for Spectral Flatness," IET Journals Mag., vol/issue: 45(23), pp. 1195 - 1196, 2009.

[25] "NorDig Unified Test Plan for Integrated Receiver Decoders for use in cable, satellite, terrestrial and IP-based networks, ver. 2.4.," 2013.

[26] H. Schulze and C. Luders, "Theory and Applications of OFDM and CDMA Wideband Wireless Communications," Chicghester, John Wiley \& Sons Ltd., 2005.

[27] ETSI, "Digital Video Broadcasting Measurement Guidelines for DVB Systems, TR 101290 - V1.2.1,” 2001. 